\title{
O PLANO NACIONAL DE EDUCAÇÃo BRASILEIRA E A POLÊMICA SOBRE O FINANCIAMENTO
}

\author{
THE BRAZILIAN NATIONAL EDUCATION PLAN AND THE CONTROVERSY \\ ABOUT THE FINANCING.
}

\author{
Antonia de Abreu Sousa ${ }^{1}$ \\ Elenilce Gomes de Oliveira ${ }^{2}$
}

\section{RESUMO}

Discute a polêmica do financiamento da educação brasileira no Plano Nacional de Educação (PNE), que vigorou de janeiro de 2001 a janeiro de 2011, e o Projeto de Lei no. 8.035/2010, que tramita no Congresso Nacional, já a dois anos, para a criação do PNE, referente ao período de dez anos. O PNE é um plano de metas e anuncia custos e recursos disponíveis para a educação. $O$ plano de 2001 a 2011, de acordo com o Ministério da Educação (MEC), só cumpriu $33 \%$ das suas metas. Um dos maiores problemas identificado pelos pesquisadores foi a quantidade de recursos financeiros, aplicados na educação, nunca passando de $5 \%$ do Produto Interno Bruto (PIB). A Conferência Nacional de Educação (CONAE) apresentou proposta para o novo PNE, sugerindo que os investimentos do PIB fossem elevados anualmente, chegando em 2014 a 10\%; a nova proposta de PNE solicita a aplicação de apenas 7\%; ainda assim, a partir de 2020. Consequentemente, os recursos propostos de7\% serão insuficientes para implementar o conjunto das metas que se anuncia para uma educação de boa qualidade para todos. A aplicação dos recursos financeiros na ordem de $10 \%$ do PIB, necessita de elevados recursos, ou seja, de US\$228 bilhões no primeiro ano de vigência. A proposta é possível, mas exigirá decerto uma priorização da educação no País como política estreita entre a União, os estados, o Distrito Federal e os municípios, redefinindo as contribuições existentes para educação.

Palavras-chave: Financiamento - Plano Nacional de Educação - Metas.

\begin{abstract}
1 Doutora em Educação Brasileira pela Universidade Federal do Ceará; pesquisadora do Laboratório de Estudos do Trabalho e Qualificação Profissional (LABOR); pesquisadora do Núcleo de Pesquisa em Educação Profissional (NUPEP); professora no Instituto Federal de Educação, Ciência e Tecnologia do Ceará (IFCE).E-mail: antonia@ifce.edu.br.

2 Doutora em Educação Brasileira pela Universidade Federal do Ceará; pesquisadora do Laboratório de Estudos do Trabalho e Qualificação Profissional (LABOR); pesquisadora do Núcleo de Pesquisa em Educação Profissional (NUPEP); professora no Instituto Federal de Educação, Ciência e Tecnologia do Ceará (IFCE).E-mail: elenilce@ifce.edu.br.
\end{abstract}


Discuss the controversial Brazilian education financing on the National Educational Plan (PNE), which was active from January 2001 to January 2011, and the law project $n^{\circ} 8,035 / 2010$, which already waited two years at the National Congress, for the creation of the PNE, referring to the period of ten years. NEP is a plan of goals and announces the costs and resources available for education. The plan from 2001 to 2011, according to the education ministry (MEC), only achieved $33 \%$ of its goals. One of the biggest problems pointed by the researchers was the amount of financial resources applied in education, which never went beyond $5 \%$ of the gross national product. The National Conference of Education (CONAE) proposed to raise the new PNE, suggested that the investments from the Gross National Product were raised annually, arriving in 2014 to $10 \%$. The new proposal of PNE requests the application of only $7 \%$, starting at 2020 . Consequently, the proposal of $7 \%$ will be insufficient to implement the group of goals that is announced for an education of good quality to everyone. The application of $10 \%$ of the National Gross Product requires elevated resources, in other words, US\$228 billion in the first active year. The proposal is possible, but will require that the education in the country is defined as a priority as a strict politic from the Union, States, Federal District and the County, redefining the existing contributions to the education.

Key-words: Financing - National Education Plan - Goals

\section{INTRODUÇÃO}

O Plano Nacional de Educação (PNE) é um plano de metas que anuncia custos e recursos disponíveis para a educação, tendo aporte legal na Constituição Federal de 1988 e na Lei de Diretrizes e Bases da Educação Nacional (LDB) de 1996.

O PNE foi aprovado pelo Congresso Nacional em dezembro de 2000 e sancionado em janeiro de 2001, mediante a Lei n‥ 10.172, de 09 de janeiro de 2001 e vigorou até janeiro de 2011.

O Congresso Nacional aprovou no PNE a aplicação de 7\% do Produto Interno Bruto $(\mathrm{PIB})^{3}$, para serem gastos com a educação brasileira, mas foi vetado pelo, então, presidente Fernando Henrique Cardoso, permanecendo o veto nos oito anos do presidente Luis Inácio Lula da Silva.

A insuficiência dos recursos aplicados na educação brasileira já é denunciada há várias décadas. O Brasil aplicou, nos últimos anos, o

\footnotetext{
${ }^{3}$ O Produto Interno Bruto (PIB) é a soma de todos os serviços e bens produzidos em uma nação, num período (mês, semestre, ano). O PIB é expresso em valores monetários e é um importante indicador da atividade econômica.
} 
equivalente a $4 \%$ do PIB, chegando a $5 \%$ apenas em 2009. O Poder Público precisa elevar o percentual do PIB para o mínimo de 10\%, o que poderia começar a expressar uma política pública preocupada com educação de melhor qualidade.

Essa discussão é recorrente e, na Conferência Nacional de Educação (CONAE), realizada em 2010, decidiu-se que o novo PNE, como política de Estado, deverá consolidar o financiamento, acompanhamento e controle social da educação, por meio da ampliação dos atuais percentuais do PIB para a educação (BRASIL, 2010c).

Em dezembro de 2010 o Governo Federal encaminhou o Projeto de Lei №. 8.035 para aprovação do PNE do decênio 2011 - 2020 em cujas diretrizes, encontra-se também o estabelecimento de meta de aplicação de recursos públicos em educação com proporção do PIB. Esta definição encontra-se estabelecida na meta 20 , que determina a ampliação progressiva do investimento público em educação para atingir, no mínimo, o patamar de 7\% do PIB até 2020.

O Projeto de Lei ํ․ 8035/2010, novo PNE, desconsidera o documento da CONAE, que recomenda ampliar proporção de $1 \%$ ao ano, de forma a atingir $10 \%$ até 2014 . Indica, ainda, fontes para os aumentos, dentre as quais recursos do Pré-Sal e dos royalties da produção de energia.

O texto aponta para conclusões de que os recursos propostos no Projeto de Lei $n^{\circ}$. 8.035/2010 serão insuficientes para implementar o conjunto das metas para melhorar a qualidade da educação brasileira.

Para o estudo, foi utilizada análise bibliográfica, particularmente centrada sobre o debate atual que envolve o financiamento no PNE e análise documental, abrangendo documentos nacionais.

\section{BREVE HISTÓRICO DO PNE 2001 A 2010}

A Constituição Federal de 1988, no artigo 214, institui a obrigatoriedade de um plano nacional para a educação de longo prazo (dez anos), com força de lei, capaz de conferir estabilidade às iniciativas governamentais na área educacional, a fim de erradicar o analfabetismo, 
universalizar o atendimento escolar, melhorar a qualidade do ensino, formar para o trabalho, para a promoção científica, tecnológica e humanística. O PNE é, portanto, um documento que estabelece tudo aquilo que o País precisa fazer para que a educação atinja níveis desejáveis de investimento, qualidade, quantidade de vagas nas escolas e universidades, entre outros ${ }^{4}$.

Após a aprovação da LDB №. 9394 de 1996, iniciou-se a discussão sobre o plano. $\mathrm{O}$ artigo 87 da referida lei previa que, até um ano após a publicação, o governo deveria encaminhar uma proposta de Plano Nacional de Educação.

Assim, o PNE foi aprovado pelo Congresso Nacional em dezembro de 2000 e sancionado em janeiro de 2001, mediante a Lei №. 10.172, de 09 de janeiro de 2001. Tem força de lei por cumprir um mandado constitucional, estendendo-se por uma década. Abrange os diferentes níveis e modalidades de ensino, bem como as demais áreas da administração educacional. Como um plano de metas, o PNE anuncia custos, recursos disponíveis e estratégias para ampliar a educação (BRASIL, 2001).

Foram muitos os questionamentos em torno do PNE, sancionado em 2001. Poucas metas foram atingidas - exatamente $33 \%$, segundo dados preliminares, divulgados pelo Ministério da Educação (BRASIL, 2010a).

É possível dizer que o maior problema foi o veto do presidente Fernando Henrique Cardoso ao dispositivo aprovado pelo Congresso ao PNE, a destinação de 7\% do PIB para o financiamento da Educação.

\section{PROPOSTA DE PNE 2011 A 2020}

A proposta de PNE para o período de 2011 a 2020 foi entregue pelo ministro da Educação, na época, Fernando Haddad, em dezembro de 2010, ao presidente Luiz Inácio Lula da Silva ${ }^{5}$. 0 documento de 14 páginas tem as

\footnotetext{
${ }^{4}$ A existência do Plano Nacional de Educação com vigência de dez anos é, em si, um fato muito importante, pois significa a possibilidade de algum grau de continuidade nas políticas educacionais; por isto, um instrumento desta natureza não pode expressar, unicamente, as proposições e intenções de uma determinada gestão.

${ }^{5} \mathrm{O}$ presidente Lula encaminhou o projeto de lei ao Congresso Nacional, que começou a discussão do texto. A previsão era de que o novo PNE fosse aprovado até o fim do primeiro semestre de 2011, mas a Câmara dos Deputados registrou até o primeiro
} 
seguintes diretrizes: Erradicação do analfabetismo; Universalização do atendimento escolar; Superação das desigualdades educacionais; Melhoria da qualidade do ensino; Formação para o trabalho; Promoção da sustentabilidade socioambiental; Promoção humanística, científica e tecnológica do País; Estabelecimento de meta de aplicação de recursos públicos em educação como proporção do produto interno bruto; Valorização dos profissionais da educação; Difusão dos princípios da equidade, do respeito à diversidade e a gestão democrática da educação.

A proposta de PNE estabelece 20 metas a ser alcançadas pelo País até 2020, conforme o quadro 1.

QUADRO 1 - Metas para o PNE 2011-2020

\begin{tabular}{|c|c|}
\hline Meta 01 & $\begin{array}{l}\text { Universalizar o ensino fundamental de nove anos para toda } \\
\text { população de } 6 \text { a } 14 \text { anos. }\end{array}$ \\
\hline Meta 02 & $\begin{array}{l}\text { Universalizar o atendimento escolar da população de } 4 \text { e } 5 \text { anos, e } \\
\text { ampliar a oferta de educação infantil para atender a } 50 \% \text { das } \\
\text { crianças de até } 3 \text { anos. }\end{array}$ \\
\hline Meta 03 & $\begin{array}{l}\text { Universalizar o atendimento escolar para toda a população de } 15 \\
\text { a } 17 \text { anos e elevar a taxa líquida de matrículas no ensino médio } \\
\text { para } 85 \% \text {. }\end{array}$ \\
\hline Meta 04 & $\begin{array}{l}\text { Universalizar, para a população de } 4 \text { a } 17 \text { anos, portadores de } \\
\text { deficiência, transtornos globais do desenvolvimento e altas } \\
\text { habilidades ou superdotação, o atendimento escolar, na rede } \\
\text { regular de ensino. }\end{array}$ \\
\hline Meta 05 & $\begin{array}{l}\text { Alfabetizar todas as crianças até, no máximo, os oito anos de } \\
\text { idade. }\end{array}$ \\
\hline Meta 06 & $\begin{array}{l}\text { Oferecer educação em tempo integral em } 50 \% \text { das escolas } \\
\text { públicas de educação básica. }\end{array}$ \\
\hline Meta 07 & 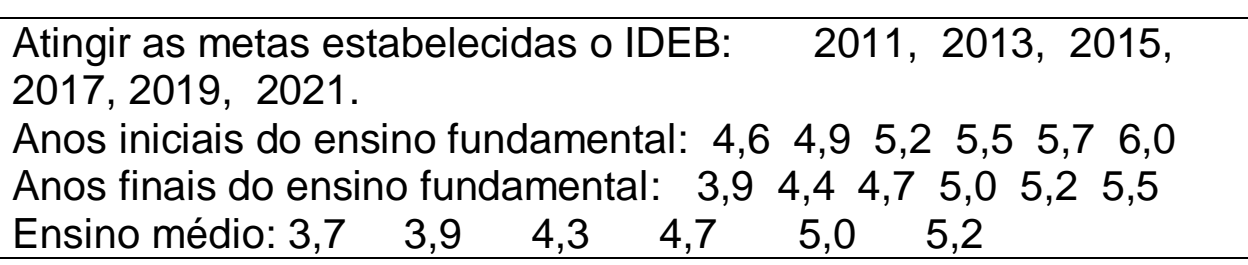 \\
\hline Meta 08 & $\begin{array}{l}\text { Elevar a escolaridade média da população de } 18 \text { a } 24 \text { anos para } \\
\text { alcançar no mínimo de } 12 \text { anos de estudo para as populações do } \\
\text { campo, da região de menor escolaridade no país e dos } 25 \% \text { mais } \\
\text { pobres, bem como igualar a escolaridade média entre negros e } \\
\text { não negros, com vistas à redução da desigualdade educacional. }\end{array}$ \\
\hline
\end{tabular}

semestre de 2012, a entrada de 2.919 emendas parlamentares que visam modificar o texto original. 


\begin{tabular}{|c|c|}
\hline Meta 09 & $\begin{array}{l}\text { Elevar a taxa de alfabetização da população com } 15 \text { anos de } \\
\text { modo a erradicar o analfabetismo absoluto e reduzir em } 50 \% \text { a } \\
\text { taxa de analfabetismo funcional. }\end{array}$ \\
\hline Meta 10 & $\begin{array}{l}\text { Oferecer, no mínimo, } 25 \% \text { das matrículas de educação de jovens } \\
\text { e adultos na forma integrada à educação profissional nos anos } \\
\text { finais do ensino fundamental e no ensino médio. }\end{array}$ \\
\hline Meta 11 & $\begin{array}{l}\text { Duplicar as matrículas da educação profissional técnica de nível } \\
\text { médio, assegurando a qualidade da oferta. }\end{array}$ \\
\hline Meta 12 & $\begin{array}{l}\text { Elevar a taxa bruta de matrícula na educação superior para } 50 \% \text { e } \\
\text { a taxa líquida para } 33 \% \text { da população de } 18 \text { a } 24 \text { anos, } \\
\text { assegurando a qualidade da oferta. }\end{array}$ \\
\hline Meta 13 & $\begin{array}{l}\text { Elevar a qualidade da educação superior pela ampliação da } \\
\text { atuação de mestres e doutores nas instituições de educação } \\
\text { superior para } 75 \% \text {, no mínimo, do corpo docente em efetivo } \\
\text { exercício, sendo, do total, } 35 \% \text { doutores. }\end{array}$ \\
\hline Meta 14 & $\begin{array}{l}\text { Elevar gradualmente o número de matrículas na pós-graduação } \\
\text { stricto sensu de modo a atingir a titulação anual de } 60 \text { mil mestres } \\
\text { e } 25 \text { mil doutores. }\end{array}$ \\
\hline Meta 15 & $\begin{array}{l}\text { Garantir, em regime de colaboração entre a União, os Estados, o } \\
\text { Distrito Federal e os Municípios, que todos os professores da } \\
\text { educação básica possuam formação específica de nível superior, } \\
\text { obtida em curso de licenciatura na área de conhecimento em que } \\
\text { atuam. }\end{array}$ \\
\hline Meta 16 & $\begin{array}{l}\text { Formar } 50 \% \text { dos professores da educação básica em nível de } \\
\text { pós-graduação lato e stricto sensu, garantir a todos formação } \\
\text { continuada em sua área de atuação. }\end{array}$ \\
\hline Meta 17 & $\begin{array}{l}\text { Valorizar o magistério público da educação básica a fim de } \\
\text { aproximar o rendimento médio do profissional do magistério com } \\
\text { mais de onze anos de escolaridade do rendimento médio dos } \\
\text { demais profissionais com escolaridade equivalente. }\end{array}$ \\
\hline Meta 18 & $\begin{array}{l}\text { Assegurar, no prazo de dois anos, a existência de planos de } \\
\text { carreira para os profissionais do magistério em todos os sistemas } \\
\text { de ensino. }\end{array}$ \\
\hline Meta 19 & $\begin{array}{l}\text { Garantir, mediante lei específica aprovada no âmbito dos Estados, } \\
\text { do Distrito Federal e dos Municípios, a nomeação comissionada } \\
\text { de diretores de escola vinculada a critérios técnicos de mérito e } \\
\text { desempenho e à participação da comunidade escolar. }\end{array}$ \\
\hline Meta 20 & $\begin{array}{l}\text { Ampliar progressivamente o investimento público em educação } \\
\text { até atingir, no mínimo, o patamar de } 7 \% \text { do produto interno bruto } \\
\text { do país. }\end{array}$ \\
\hline
\end{tabular}

Fonte: Projeto de Lei №. 8035 de 2010.

Cada uma das metas é acompanhada de estratégias para que se atinjam os objetivos delimitados que são: elevar a escolaridade da população, melhorar a qualidade de ensino e reduzir as desigualdades. Algumas desses objetivos já foram previstos em leis aprovadas recentemente ou fazem parte do PNE de 2001 a 2011. 
O PNE traça os objetivos e tem a finalidade de orientar os esforços da União, dos governos estaduais, distrital e municipais. Assim sendo, a implementação do plano é de responsabilidade dos diferentes níveis de governo, que precisam ainda criar seus planos de ação.

O grave problema enfrentado pelo plano de 2001 a 2011 foi que a maioria dos municípios e estados não aprovou uma legislação que garantisse recursos suficientes para financiar uma educação de boa qualidade. A União também não o fez.

Para a nova versão do PNE, as entidades ligadas à Educação defendem $o$ argumento de que haja a determinação clara da origem dos recursos e da área em que devem ser investidos. Se isto ocorrer, o PNE pode colaborar para a luta por uma educação pública de melhor qualidade. Caso contrário, o Plano fracassará, como ocorreu com o de 2001 - 2011.

\section{POUCOS RECURSOS FINANCEIROS PARA EDUCAÇÃO BRASILEIRA}

A insuficiência dos recursos aplicados na educação brasileira já é denunciada há várias décadas. Ofertar educação de boa qualidade não é possível com poucos recursos. O Brasil aplicou, nos últimos anos, o equivalente a $4 \%$ do PIB. O Poder Público tem de investir mais para mudar a situação do ensino brasileiro. O gráfico 1 demonstra que, de 1999 a 2009, o crescimento dos recursos para educação foi de $0,7 \%$.

Gráfico 1 - Gasto Público com Educação em Relação ao PIB - Brasil - 19992009 


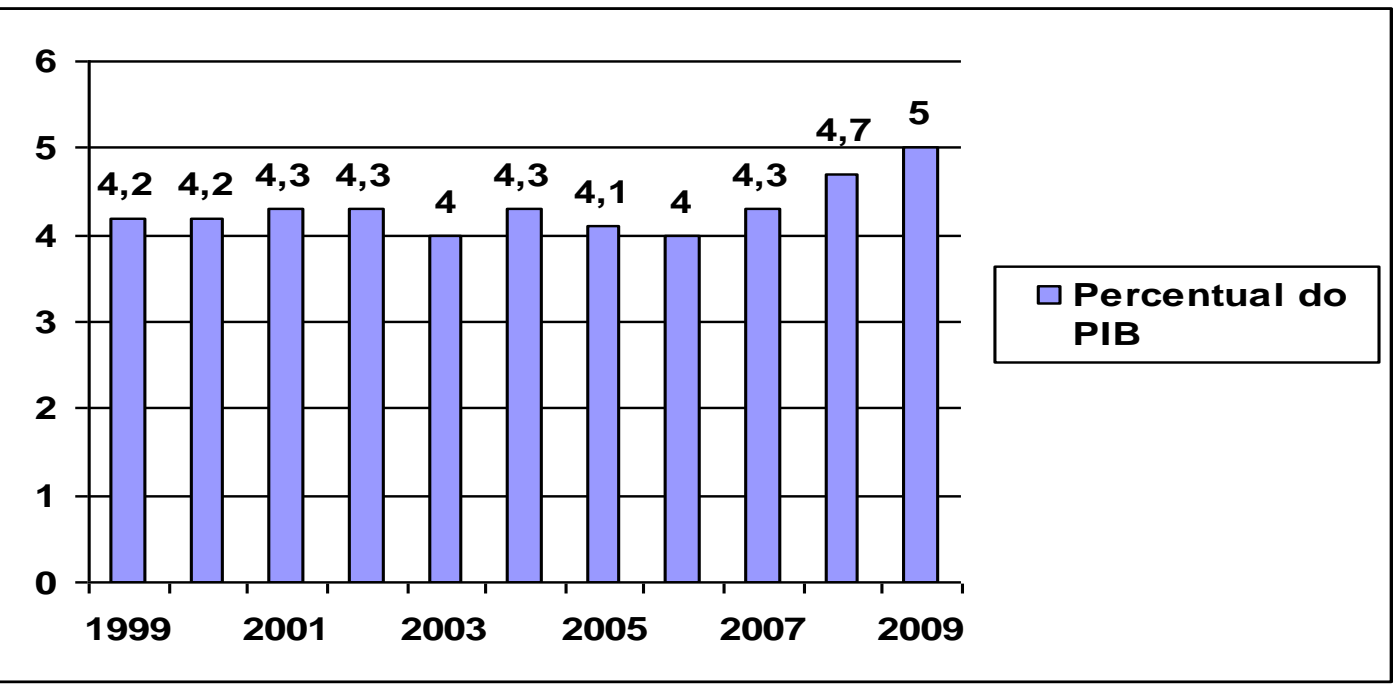

Fonte: Ipea/Disoc, STN (dados de 1996 - 2002), os dados de 2003 -2005 têm como fonte: o Ipea/Disoc, STN/Siafi e Castro \& Duarte (2008), MEC (2009). Elaboração: SOUSA, Antonia de Abreu \& OLIVEIRA, Elenilce Gomes.

Com base neste gráfico, observa-se que, em nove anos, o Brasil modificou, em pequenos percentuais, seu crescimento no investimento educacional. Pode-se dizer que as alterações mais significativas aconteceram com origem em 2007, em menos de $1 \%$.

Para se entender melhor as razões do debate em torno do financiamento educacional, é importante verificar, além do nível de investimento público em relação ao PIB, outros indicadores, como o valor por aluno/ano, o dispêndio em educação relacionado ao custo total do Governo e, por fim, a característica da população, no que se refere à quantidade de pessoas em idade escolar, compreendendo a população total.

O Brasil tem um gasto por aluno/ano de US\$ 832, no ensino fundamental, enquanto em países-membros da Organização de Cooperação e de Desenvolvimento Económico (OCDE) $)^{6}$ o custo é em torno de US $\$ 4.850$ por aluno/ano, o que equivale a 5,8 vezes o total verificado, no mesmo nível de ensino (SOUSA, 2009).

A Nação brasileira consta abaixo do Chile (US\$2.110), da Argentina (US\$ 1.650) e do Uruguai (US\$1.202) e um pouco acima do Paraguai (US\$

\footnotetext{
${ }^{6}$ Os países membros da OCDE são: Austrália, Áustria, Alemanha, Bélgica, Canadá, Coréia do Sul, Dinamarca, Espanha, Estados Unidos, Finlândia, França, GrãBretanha, Grécia, Holanda, Hungria, Islândia, Irlanda, Itália, Japão, Luxemburgo, México, Nova Zelândia, Noruega, Polônia, Portugal, República Tcheca, Suécia, Suíça e Turquia.
} 
802); mais distante do Peru, que aplica somente US\$ 431 por aluno/ano (BORGES, 2007, apud SOUSA, 2009).

Se a análise for feita em relação às despesas totais nos países da OCDE para um valor por aluno de US\$ 4.850, a educação absorve $12,7 \%$ do gasto público, enquanto no Brasil, para garantir um importe por aluno de somente US\$ 832, a área educacional gasta a mesma proporção, ou seja, $12 \%$ do gasto público. Este fato ocorre em razão do grande contingente de jovens brasileiros em idade escolar, em relação ao quantitativo geral da população, ensejando elevado nível de matrículas. Vejamos o gráfico 2, que apresenta a quantidade populacional do Brasil e da França na série de 1997 a 2006.

Gráfico 2 - População Total - Brasil e França - 1997 a 2006

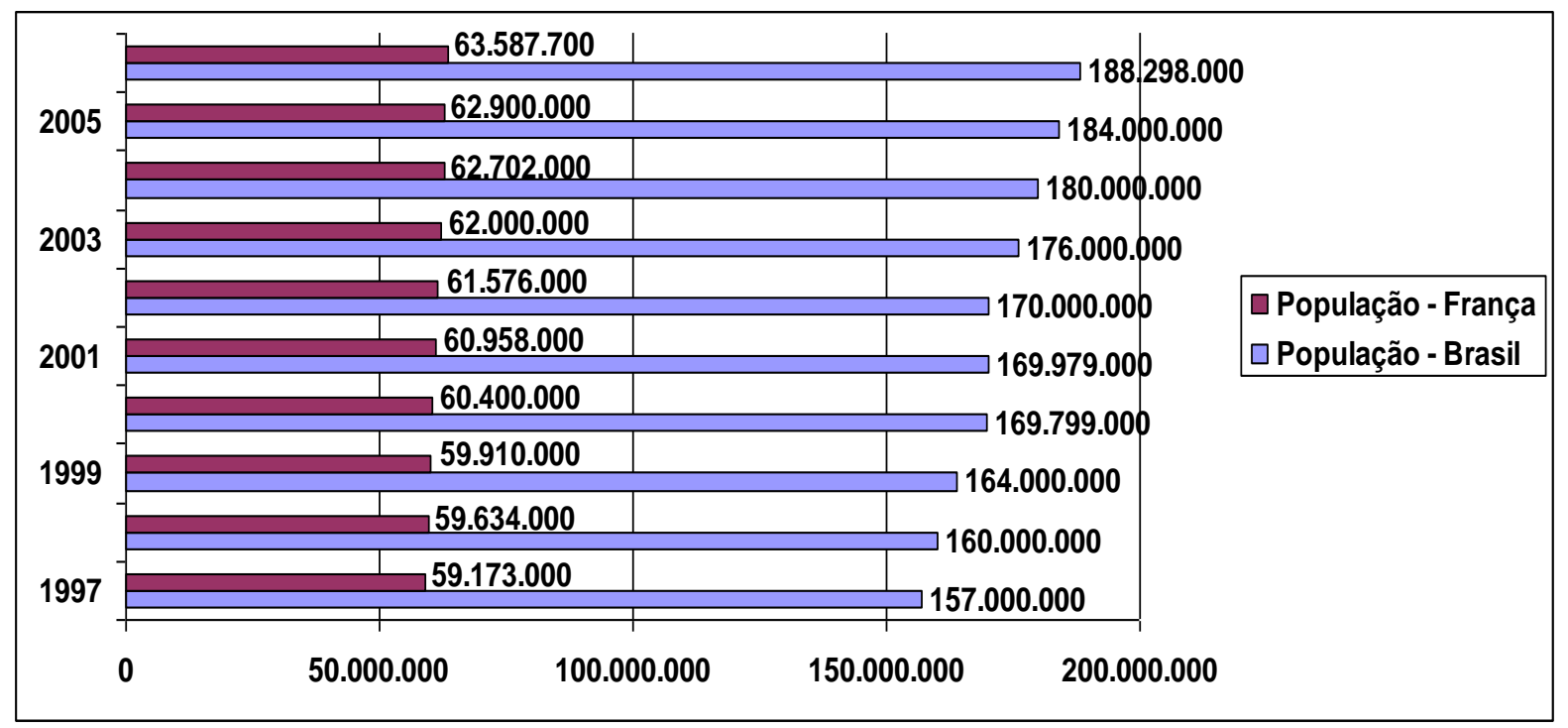

Fonte: IBGE, Diretoria de Pesquisas, Censo Populacional - 1997-2006 / www.wikipedia.pt (1) Dados estimados e aproximados pelas autoras, tanto no caso brasileiro quanto francês. Elaboração: SOUSA, Antonia de Abreu \& OLIVEIRA, Elenilce Gomes.

Situação inversa é verificada em países da OCDE. Para as razões do baixo investimento no custo/aluno brasileiro, é ilustrativo verificar, no gráfico a seguir, a população em idade escolar no Brasil e na França, país da OCDE.

Gráfico 3 - População em Idade Escolar - 1997 a 2006 


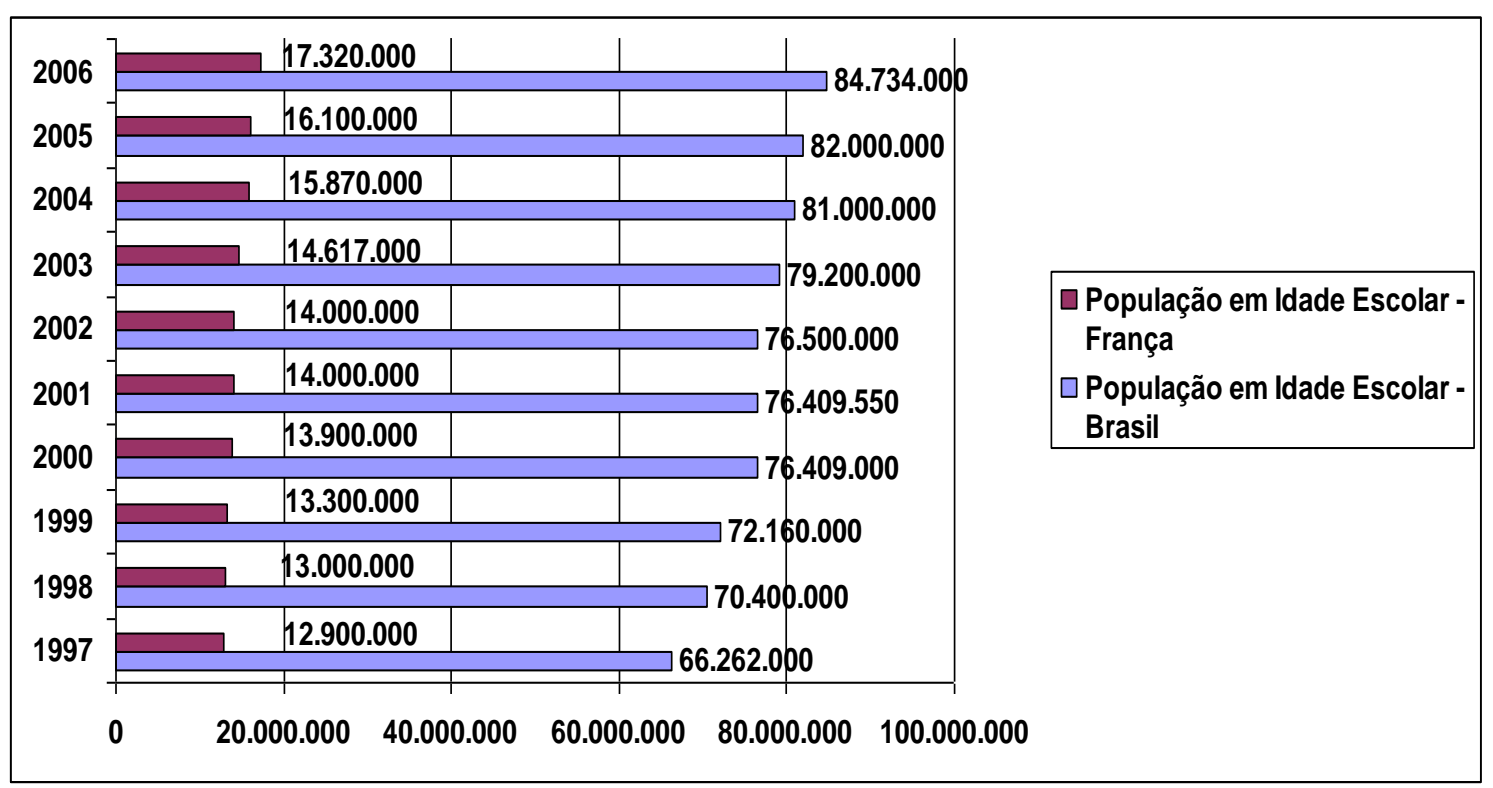

Fonte: IBGE, Diretoria de Pesquisas, Censo Populacional - 1997-2006 / www.wikipedia.pt (1) Dados estimados e aproximados pelas autoras, tanto no caso brasileiro quanto francês. Elaboração: SOUSA, Antonia de Abreu \& OLIVEIRA, Elenilce Gomes.

Persiste o debate em torno do percentual do PIB destinado à educação. O próprio Governo federal reconhece a insuficiência do total dos gastos em educação. Em 2001, é apresentado pelo Governo brasileiro o relatório do Grupo de Trabalho sobre Financiamento da Educação, criado para estudar o assunto, cuja conclusão é de que, para atingir os novos patamares de atendimento em qualidade e quantidade, definidos pelo PNE, o Brasil deveria sair do atual patamar de gastos públicos em educação, da ordem de 4,3\% do PIB, para atingir, em dez anos, o montante de $8 \%$ do PIB (RELATÓRIO, 2001, p. 117).

Em setembro de 2007, foi divulgado outro importante relatório, este internacional, sobre a questão educacional brasileira - o Education at a Glance 2007, ou seja, Educação em Rápida Visão, elaborado pela $\mathrm{OCDE}^{7}$. Na análise dos dados brasileiros, citados no mencionado documento, desponta a inevitável interpretação de que os investimentos em educação no Brasil se encontram muito aquém do necessário, quando comparados com a média dos

7 Embora o Brasil não faça parte da OCDE, mas por ser considerado um importante parceiro econômico, teve também os dados do seu sistema educacional incluídos no referido relatório. 
países da OCDE, sendo insuficientes para o enfrentamento das históricas demandas da área.

O Brasil, no período 1994-2005, gastou apenas a média de 3,9\% do seu PIB em educação, somando-se os aportes públicos e privados para todo 0 seu sistema de ensino, do nível fundamental à universidade, contra a média de $6,2 \%$ do PIB, contabilizada para a mesma finalidade entre os países da OCDE (RELATÓRIO, 2007).

Conforme o Education at a Glance, a Coreia do Sul, a Dinamarca, os Estados Unidos, e mesmo a pequena Islândia, investem mais de $7 \%$ de seus PIBs em educação. Segundo o relatório, a Nova Zelândia e a Suécia investem mais de $6,5 \%$ de seus PIBs em prol da mesma finalidade (RELATÓRIO, 2007).

O relatório da OCDE informa que, no ensino superior, o Brasil investe apenas $0,7 \%$ do seu PIB. Neste âmbito da educação, vale mencionar, os Estados Unidos destinam 2,9\% do PIB ao ensino superior, para o aporte de $7,4 \%$ da soma de todas as riquezas do País investidas em educação. $\mathrm{Na}$ Coreia do Sul, por seu turno, o percentual reservado para o ensino superior é de $2,3 \%$, em meio ao investimento total em educação, da ordem de $7,2 \%$ do PIB.

O relatório da OCDE ratifica a tese de que o Brasil investe poucos recursos com a educação, que é urgente sair do patamar de $4,3 \%$ ou $5 \%$ do PIB e elevar este percentual para o mínimo de 7\%, o que poderia começar a expressar uma política pública preocupada com educação de alta qualidade.

\section{A POLÊMICA DO FINANCIAMENTO NO PNE PARA O PERÍODO DE 2011- 2020}

Realizada em Brasília, no período de 28 de março a $1^{\circ}$ de abril de 2010, a CONAE, com o objetivo de traçar os rumos que o Brasil deve tomar em relação a todos os níveis e modalidades de ensino. Dessa conferência, saíram as diretrizes para o novo Plano Nacional de Educação (PNE) de 2011 a 2020.

$O$ plano que tramita no Congresso Nacional apresenta a meta de investimento de $7 \%$ do Produto Interno Bruto (PIB) na área. Na CONAE, a proposta apresentada foi de que, a partir de 2014, os investimentos do PIB 
para educação fossem elevados para 10\%. O PNE, no entanto, previu a aplicação de 7\%, ainda assim a partir de 2020.

A proposta de PNE foi precedida por conferências municipais, estaduais e nacional, o que garantia alta taxa de legitimidade, mas o que foi apresentado com relação ao financiamento não representa o espelhamento das proposições aprovadas na plenária final da CONAE.

Existe um número de discrepâncias entre o "Documento Final" da CONAE e o Projeto de Lei ํo. 8035/2010, sendo a meta de número 20, o financiamento, a mais complicada; ela propõe a ampliação, progressiva, dos investimentos públicos em educação até $7 \%$ do PIB, em 2020. O documento da CONAE, por sua vez, recomenda esta ampliação na proporção de $1 \%$ ao ano, de modo a atingir $10 \%$ até 2014 . Além dos percentuais, ele dá indicações das fontes de tais provimentos: aumentos das vinculações dos recursos para educação, recursos do Pré-Sal e dos royalties da produção de energia. (BRASIL, 2010c).

O Projeto de Lei №. 8.035/2010, também, não adotou a proposta aprovada na Conferência do aumento das vinculações dos recursos para a educação de $18 \%$ para $25 \%$, no caso da União, e de $25 \%$ para $30 \%$, para municípios e estados. $\mathrm{O}$ argumento utilizado foi o de que o PNE não pode fazer tal proposição; se é verdade, o Governo poderia tê-las encaminhado por meio da proposição de emenda constitucional (BRASIL, 2010c).

Outra deliberação da CONAE, não acatada pelo MEC, diz respeito ao "Custo Aluno-Qualidade" como padrão de referência para o financiamento da educação; do ponto de vista legal, bastaria ao ministro da Educação homologar a Resolução 8/2010, do Conselho Nacional de Educação, favorável à adoção.

\section{CONSIDERAÇÕES FINAIS}

À vista de tal quadro, pode-se perguntar se os recursos propostos serão suficientes para implementar o conjunto das metas que se anuncia. È possível se dizer, com boa dose de segurança, que não. Se os vetos que Fernando Henrique Cardoso imprimiu ao PNE 2001 o reduziram a uma simples 
carta de intenções, a aprovação do Projeto de Lei №. 8.035/2010, como está proposto, será conduzido por caminhos semelhantes.

A aplicação dos recursos financeiros na ordem de $10 \%$ do PIB, como recomendado pela CONAE, necessita de elevados recursos, conforme Amaral (2011), inicialmente, de US\$ 228 bilhões em 2011 e US\$ 306 bilhões em 2020. A proposta é possível, porém, não é utópica. Esta situação exigirá decerto uma priorização da educação no País como política estreita entre a União, os estados, o Distrito Federal e os municípios, para:

1) redefinir as contribuições existentes para educação;

2) controlar os recursos (aplicação de penalidades severas para desvios de verbas educacionais); e

3) estabelecer novas contribuições dirigidas para a educação, com suporte nos recursos do Fundo Social do Pré-Sal; dos créditos advindos do pagamento de royalties decorrentes de atividades de produção energética (extração, tratamento, armazenagem e refinamento de hidrocarbonetos).

Somente dessa forma, o PNE que tramita (dois anos) no Congresso Nacional não trilhará o caminho do PNE (2001-2011). A aprovação de 10\% dos recursos do PIB, no Brasil pode contribuir significativamente para "(...) o salto de qualidade necessário para colocar a educação brasileira num patamar civilizado, condizente com a magnitude de seu território, de sua população e de sua economia" (SAVIANI, 2008, p. 321).

\section{REFERÊNCIAS}

AMARAL, N. Cardoso. O novo PNE e o financiamento da educação no Brasil: os recursos como um percentual do PIB. Disponível em: $<$ www.cedes.unicamp.br/seminario3/nelson amaral.pdf. $>$. Acesso: 21 mar. 2011.

BRASIL. Plano Nacional de Educação. Ministério da Educação e do Desporto. Brasília, 2001. 
Ministério da Educação. Instituto Nacional de Estudos e Pesquisas Educacionais Anísio Teixeira (INEP). Avaliação do Plano Nacional de Educação, 2001-2008. Brasília, DF, MEC/INEP, 2010a. Disponível em: $<$ http://portal.mec.gov.br/index.php?option=com_content\&view=article\&id=1495 0:80-seminario-reuni-27-a-29-de-janeiro-de-2010 >. Acesso em: 08 abr. 2011.

Projeto de Lei no. 8035 de 2010. Câmara dos Deputados. Brasília, 2010b.

- Documento Final da Conferência Nacional de Educação CONAE/Ministério da Educação. Brasília, 2010c.

CASTRO, Jorge Abrahão de, DUARTE, Bruno de Carvalho. Descentralização da educação pública no Brasil: trajetória dos gastos e das matrículas. Brasília: IPEA, 2008 (Mimeo).

RELATÓRIO. Grupo de Trabalho sobre Financiamento da Educação. Revista Brasileira de Estudos Pedagógicos. Brasília, v. 82, jan./dez. 2001.

RELATÓRIO. Education at Glance 2007. Disponível em: <www.oecd.org.> Acesso em: 12 fev. 2008.

SAVIANI, Dermeval. Da nova LDB ao FUNDEB: por uma outra política educacional. Campinas, SP: Autores Associados, 2008.

SOUSA. Antonia de Abreu. A política de fundo público para o financiamento da educação básica: impacto e impasses no município de Fortaleza. 2009. 323 f. Tese (Doutorado em Educação) - Faculdade de Educação, Universidade Federal do Ceará, Fortaleza, 2009.

RECEBIDO EM: 21.12 .12

APROVADO: 05.01 .13 